\title{
Persepsi Masyarakat terhadap Kandungan Alkohol Pada Kosmetik
}

\section{Community Perception of Alcohol Contents in Cosmetics}

\author{
Nurkhasanah ${ }^{1 *}$, Amalya Nurul ${ }^{2}$, Farah Qisth Albab ${ }^{1}$ \\ 1. Faculty of Pharmacy, Universitas Ahmad Dahlan, Yogyakarta \\ 2. Faculty of Industrial Technology, Universitas Ahmad Dahlan, Yogyakarta \\ Submitted: 18-05-2020 Revised: 14-10-2020 Accepted: 18-12-2020 \\ Korespondensi : Nurkhasanah Mahfudh : Email : suwendarsuwendar48@gmail.com
}

\begin{abstract}
ABSTRAK
Persepsi merupakan tanggapan individu mengenai suatu hal yang dapat dipengaruhi oleh pengetahuan. Pengetahuan individu yang baik mengenai alkohol akan mempengaruhi persepsinya terhadap produk-produk yang mengandung alkohol. Fatwa MUI membolehkan penggunaan pengunaan alkohol pada kosmetik. Penelitian ini bertujuan untuk mengetahui persepsi masyarakat terhadap kandungan alkohol pada kosmetik. Teknik observasional survey menggunakan kuesioner dengan teknik sampling non probability berupa accidental sampling digunakan dalam penelitian. Analisis hasil kuesioner dilakukan menggunakan uji pearson correlation, uji validitas, uji reliabilitas, uji normalitas, uji chi square, dan deskripsi. Pada penelitian ini menggunakan 98 responden dan mendapatkan nilai rata-rata pengetahuan mengenai kosmetik 6,73 dengan nilai SD 0,49; pengetahuan alkohol 4,54 dengan SD 1,17 dan perilaku 7,10 dengan nilai SD 1,46. Terdapat hubungan usia dengan tingkat pengetahuan kosmetik dengan nilai $p$-value $<0,05$. Sebanyak $46,94 \%$ merasa urgensi label halal pada kosmetik sangat penting dan $39,80 \%$ penting, dimana agama yang dimiliki individu mempengaruhi tingkat urgensi halal kosmetik. Urgensi label halal pada kosmetik yang tinggi sejalan dengan perilaku saat membeli kosmetik, $81,63 \%$ responden merasa bahwa adanya label halal pada produk kosmetik mempengaruhi minat membeli kosmetik. Sejumlah 61,24\% responden memiliki persepsi bahwa kosmetik halal tidak mengandung alkohol. Hal ini dipertegas dengan uji pearson correlation label halal didapat nilai p-value 0,024 bahwa label halal mempengaruhi persepsi responden. Individu memiliki persepsi kosmetik berlabel halal tidak mengandung alkohol yang dipengaruhi oleh pengetahuan label halal.
\end{abstract}

Kata kunci: alkohol; halal; kosmetik

\section{ABSTRACT}

Perception is an individual response about something that can be influenced by knowledge. Good individual knowledge of alcohol will affect their perception of alcohol-containing product. The MUI fatwa permits the use of alcohol in cosmetics. The purpose of this study was to observe the perception of alcohol content in cosmetics. The observation was carried out using a questionnaire technique with a nonprobability sampling technique with accidental sampling. The questionnaire was conducted by Pearson correlation test, validity test, reliability test, normality test, chi-square test, and description. In this study, using 98 respondents and get an average value of knowledge about cosmetics 6,73 with SD value of 0,49; knowledge of alcohol 4,54 with SD 1,17 and behavior with SD 1,46. There is a relationship between age with the level of cosmetic knowledge with $p$-value $<0.05$. As many as $46.94 \%$ stated, the halal label's urgency on cosmetics is very important and $39.80 \%$ is important, where the religion of the individual influences the urgency level of cosmetics halal. The urgency of halal labels on cosmetics is high in line with the behavior when buying cosmetics. The $81.63 \%$ of respondents stated that halal labels on cosmetic products affect the interest in buying cosmetics. As many as $61.24 \%$ of respondents have the perception that halal cosmetics do not contain alcohol. The Pearson halal label correlation test confirms this obtained a p-value value of 0.024 that the halal label influences respondents' perceptions. Individuals were having a perception that cosmetics with halal labels do not contain alcohol, which is influenced by halal labels' knowledge.

Keywords: alcohol; halal; cosmetics 


\section{PENDAHULUAN}

Persepsi adalah stimulus dari alat indera ataupun sensoris yang selanjutnya akan mengalami proses sehingga terjadi persepsi ${ }^{1}$ yang dapat dipengaruhi oleh faktor internal dan faktor eksternal juga terdapat indikator persepsi salah satunya adalah pengetahuan. Pengetahuan dan perilaku yang baik yang dimiliki oleh individu mengenai halal memiliki persepsi yang baik terhadap halal ${ }^{2}$.

Individu yang memiliki pengetahuan yang baik mengenai alkohol akan memiliki persepsi yang baik juga mengenai alkohol. Alkohol atau etanol merupakan senyawa organik yang bisa didapat dari pati tumbuhan dengan menggunakan proses fermentasi, gelatinisasi yang ${ }^{3}$ dan bisa didapat dari gas alam dengan metode tekanan uap panas akan menghasilkan kadar $90-99,9 \%$ yang digunakan sebagai industri, farmasi, campuran miras dan bahan bakak ${ }^{4}$.

Pada kalangan masyarakat sebutan kata alkohol lebih sering merujuk kepada sesuatu yang dilarang oleh agama islam. Padahal dalam surat Al-Maidah ayat 90 yang diharamkan adalah khamr "Hai orang-orang yang beriman, sesungguhnya (meminum) khamr, judi, (berkorban untuk) berhala, dan mengundi nasib dengan panah adalah termasuk perbuatan-perbuatan syaitan. Maka jauhilah perbuatan-perbuatan itu agar kamu mendapat keberuntungan" dan pada hadist "Barangsiapa yang diberikan wewangian, hendaknya ia tidak menolak. Sebab ia mudah dibawa dan baunya harum (HR. Muslim, Nasai dan abu Daud)." Hukum penggunaan bahan alkohol atau etanol dalam bahan campuran pembuatan kosmetik adalah mubah asal alkohol atau etanol pada produk kosmetik yaitu diperbolehkan asal tidak berasal dari industri khamr dan tidak membahayakan $^{5}$

Label halal memiliki peran penting baik untuk produsen dan konsumen. Salah satu peran penting bagi produsen adalah meningatkan rasa percaya dan puas bagi konsumen, sedangkan bagi konsumen adalah terlindungnya konsumen muslim dari barang seperti makanan, minumam, obat, dan kosmetik yang tidak halal, memberi rasa tenang pada batin dan hati, mempertahankan jiwa dan raga dari produk haram dan kepastian serta perlindungan hukum ${ }^{6}$.

Peluang pasar kosmetik halal sudah menjadi kebutuhan global wilayah Asia merupakan pasar halal yang cukup besar sebesar $63.3 \%$ dengan terjadi peningkatan $6,9 \%$ pendapatan dari penggunaan kosmetik berupa kecantikan dan alat make $u p^{7}$. Peningkatan pasar halal berdampak pada produksi kosmetik halal. Hal ini disebabkan karena label halal pada suatu produk dapat mempengaruhi persepsi individu ${ }^{8}$ yang dapat mempengaruhi keputusan dan penggunaan produk halal ${ }^{9}$. Terdapat kadar etanol 7,31 $611,64 \mu \mathrm{g} / \mathrm{mL}$ pada parfum yang diklaim alcohol-free yang beredar di Malaysia ${ }^{10}$. Kandungan alkohol juga ditemukan pada produk mouthwash yaitu dari 12 sampel mothwash yang diteliti hanya 2 sampel mouthwash yang negatif tidak mengandung alkohol dan terdapat 2 sampel yang mengklain produknya free alcohol ternyata positif mengandung alkohol ${ }^{11}$.

Berdasarkan uraian diatas dapat diketahui bahwa penggunaan label halal pada suatu produk dapat mempengaruhi konsumen secara langsung terhadap persepsi suatu barang tersebut. Oleh karena itu dilakukannya penelitian mengenai persepsi masyarakat terhadap kandungan alkohol pada produk kosmetik berlabel halal.

\section{METODE}

Desain penelitian menggunakan metode observasional survey analisis dengan menggunakan populasi yaitu individu yang berada dilingkungan kampus dengan metode sampling yaitu non probability sampling accidental sehingga hanya individu yang bertemu dengan peneliti. Hasil kuesioner yang telah didapatkan akan dianalisis dengan menggunakan alat bantu Microsoft Excel dan SPSS 23.0 
Tabel I. Daftar Demografi Responden

\begin{tabular}{lcc}
\hline & Frekuensi & Persentase(\%) \\
\hline Usia & & \\
$18-25$ tahun & 94 & 95,92 \\
26 - 30 tahun & 4 & 4,08 \\
$>30$ tahun & - & - \\
Jenis kelamin & & \\
Perempuan & 87 & 88,78 \\
Laki-laki & 11 & 11,22 \\
Agama & & \\
Islam & 95 & 96,94 \\
Kristen & 3 & 3,06 \\
Katolik & - & - \\
Hindu & - & - \\
$\quad$ Budha & - & - \\
Pekerjaan & & 3,06 \\
$\quad$ Pelajar (SMP atau SMA) & 3 & 92,86 \\
Mahasiswa & 91 & 2,04 \\
Pegawai Negeri atau Swasta & 2 & 2,04 \\
Wirausaha atau Wiraswasta & 2 & - \\
Ibu Rumah Tangga & - & - \\
$\quad$ Lainnya & - & \\
\hline
\end{tabular}

\section{Analisis Data}

Analisis data kuesioner dilakukan secara statistik dan desktriptif. Analisis statistik dengan melakukan beberapa uji seperti pengujian intrumen kuesioner yang terdiri dari uji validitas dan uji reliabilitas. Uji prasyarat analisis seperti uji kecukupan data, uji homogenistas, dan uji normalitas. Serta uji correlation, uji spearman rank, uji chi square.

\section{HASIL DAN PEMBAHASAN}

\section{Demografi responden}

Pada tabel I dapat dilihat mayoritas responden pada penelitian adalah mahasiswa $(92.86 \%)$, berjenis kelamin perempuan $(88.78 \%)$ dan beragama islam $(96.04 \%)$ Nilai rata-rata pengetahuan responden terhadap kosmetik dan alkohol memiliki nilai rata-rata yang rendah yaitu 6,73 dan 4,54. Begitu juga dengan mahasiswa jurusan kesejahteraan masyarakat yang telah belajar tentang perawatan diri ternyata masih memiliki pengetahuan yang kurang pada kosmetik ${ }^{12}$. Nilai rata-rata perilaku responden yaitu 7,10 sudah cukup bagus, dimana faktor yang mempengaruhi perilaku seperti faktor kebudayaan, faktor sosial, faktor pribadi dan faktor psikologis

\section{Pengetahuan Responden}

Pada data demografi sebagian besar responden sudah menyelesaikan tingkat sekolah menegah atas (SMA). Pendidikan dan pekerjaan yang berbeda antar responden ternyata memiliki dampak terhadap perbedaan pengetahuan tiap individu.

Setengah dari jumlah responden memiliki pengetahuan yang baik mengenai alkohol dan kosmetik, hanya usia yang memiliki pengaruh terhadap tingkat pengetahuan dengan nilai $\quad$-value $<0,05$ sedangan untuk kategori lain tidak terdapat hubungan dengan tingkat pengetahuan dikarenakan pengetahuan tidak memihak pada gender melainkan kepada minat, lingkungan dan sikap kepedulian ${ }^{13}$.

\section{Perilaku responden}

Perilaku responden pada penelitian ini juga berada pada kategori baik, namun tingkat 
Tabel II. Hubungan status demografi terhadap skor rata-rata pengetahuan

\begin{tabular}{|c|c|c|c|c|}
\hline \multirow{2}{*}{ Demografi responden } & \multicolumn{3}{|c|}{ Tingkat Pengetahuan (n) } & \multirow{2}{*}{ p-value } \\
\hline & Baik & Cukup & Kurang & \\
\hline \multicolumn{5}{|l|}{ Kosmetik } \\
\hline \multicolumn{5}{|l|}{ Usia } \\
\hline 18-25 tahun & 31 & 62 & 1 & $0,006^{*}$ \\
\hline 25-30 tahun & 4 & - & - & \\
\hline \multicolumn{5}{|l|}{ Jenis kelamin } \\
\hline Laki-laki & 6 & 5 & - & 1,000 \\
\hline Perempuan & 29 & 57 & 1 & \\
\hline \multicolumn{5}{|l|}{ Pendidikan terakhir } \\
\hline SMP & 1 & 1 & - & \\
\hline SMA & 32 & 58 & 1 & 0,974 \\
\hline Sarjana & 2 & 3 & - & \\
\hline \multicolumn{5}{|l|}{ Alkohol } \\
\hline Usia & 31 & 43 & 20 & 0,085 \\
\hline 18-25 tahun & 3 & 1 & - & \\
\hline \multicolumn{5}{|l|}{ 25-30 tahun } \\
\hline \multicolumn{5}{|l|}{ Jenis kelamin } \\
\hline Laki-laki & 2 & 6 & 3 & 0,193 \\
\hline Perempuan & 32 & 38 & 17 & \\
\hline \multicolumn{5}{|l|}{ Pendidikan terakhir } \\
\hline SMP & 1 & 1 & - & \\
\hline SMA & 32 & 58 & 1 & 0,972 \\
\hline Sarjana & 2 & 3 & - & \\
\hline
\end{tabular}

Keterangan: * terdapat perbedaan yang p-valuenifikan

Tabel III. Hubungan status demografi terhadap perilaku

\begin{tabular}{|c|c|c|c|}
\hline \multirow{2}{*}{ Demografi responden } & \multicolumn{2}{|c|}{ Tingkat Perilaku } & \multirow{2}{*}{ p-value } \\
\hline & Baik & Kurang & \\
\hline \multicolumn{4}{|l|}{ Usia } \\
\hline 18-25 tahun & 64 & 30 & 0,179 \\
\hline 25-30 tahun & 4 & - & \\
\hline \multicolumn{4}{|l|}{ Jenis kelamin } \\
\hline Laki-laki & 5 & 6 & 0,087 \\
\hline Perempuan & 63 & 24 & \\
\hline \multicolumn{4}{|l|}{ Pendidikan terakhir } \\
\hline SMP & 2 & - & \\
\hline SMA & 63 & 28 & 0,381 \\
\hline Sarjana & 3 & 2 & \\
\hline
\end{tabular}

perilaku tidak ada hubungan dengan latar belakang status demografi responden dengan nilai $p$-value $>0,05$. Perilaku bisa muncul karena adanya hubungan timbal balik yang dikenal oleh rangsangan tanggapan dari luar dengan respon akan membentuk perilaku yang baru. Perilaku individu dapat dipengaruhi oleh adat, sikap, emosi, nilai etika, kekuasaan, persuasi, dan genetika yang saling terkait secara berkesinambungan yang akan mempengaruhi perilaku ${ }^{14}$. 
Nurkhasanah, et al

Tabel IV. Urgensi label halal pada pangan, kosmetik dan produk kosmetik yang beredar

\begin{tabular}{|c|c|c|c|c|c|}
\hline \multirow{2}{*}{$\begin{array}{l}\text { Demografi } \\
\text { responden }\end{array}$} & \multicolumn{5}{|c|}{ Tingkat urgensi (n) } \\
\hline & $\begin{array}{l}\text { Sangat } \\
\text { penting }\end{array}$ & Penting & Biasa saja & $\begin{array}{c}\text { Tidak } \\
\text { penting }\end{array}$ & $\begin{array}{c}\text { Sangat tidak } \\
\text { penting }\end{array}$ \\
\hline \multicolumn{6}{|c|}{ Pangan } \\
\hline \multicolumn{6}{|c|}{ Pendidikan akhir } \\
\hline SMP & 2 & - & - & - & - \\
\hline SMA & 73 & 16 & - & 2 & - \\
\hline Sarjana & 5 & - & - & - & - \\
\hline \multicolumn{6}{|l|}{ Agama } \\
\hline Islam & 80 & 15 & - & - & - \\
\hline Kristen & - & 1 & - & 2 & - \\
\hline \multicolumn{6}{|l|}{ Kosmetik } \\
\hline \multicolumn{6}{|c|}{ Pendidikan akhir } \\
\hline SMP & 1 & - & 1 & - & - \\
\hline SMA & 43 & 36 & 12 & - & - \\
\hline Sarjana & 2 & 3 & - & - & - \\
\hline \multicolumn{6}{|l|}{ Agama } \\
\hline Islam & 46 & 39 & 10 & - & - \\
\hline Kristen & - & - & 3 & - & - \\
\hline
\end{tabular}

Tabel V. Faktor utama pada saat membeli kosmetik

\begin{tabular}{lccccc}
\hline \multirow{2}{*}{ Demografi responden } & \multicolumn{5}{c}{ Faktor membeli kosmetik (n) } \\
\cline { 2 - 5 } & Kebutuhan & Kehalalan & Kualitas & Harga & Brand \\
\hline Usia & 38 & 23 & 17 & 13 & 3 \\
$\begin{array}{l}18-25 \text { tahun } \\
25-30 \text { tahun }\end{array}$ & 3 & 1 & - & - & - \\
Agama & & & & & \\
Islam & 40 & 24 & 17 & 2 & - \\
Kristen & 1 & - & - & & 3 \\
\hline
\end{tabular}

\section{Urgensi label halal}

Sebanyak $81.63 \%$ responden yang beranggapan bahwa label halal pada produk pangan sangat penting (Tabel IV) namun terdapat $2.04 \%$ responden yang merasa label halal pada produk pangan tidak penting dan diketahui beragama kristen disebabkan oleh faktor kebiasaan, norma dan adat, serta lingkungan agama tersebut. Berbeda dengan orang di Inggris mengkonsumsi daging halal dan merasa lebih aman ${ }^{15}$.

Tingkat kesadaran halal juga terjadi pada produsen kosmetik halal di Malaysia ${ }^{16}$. Pada penelitian ini selisih urgensi label halal pangan dan kosmetik yang sedikit berbeda. Hal ini disebabkan karena keraguan individu terhadap penggunaan produk halal jika tidak ada manfaat potensil yang dirasakan serta tidak sesuai dengan gaya hidup individu itu sendiri. Setelah dilakukan moderenisasi kosmetik halal memiliki kelebihan dari keamaan dan kualitas produk ${ }^{17}$ serta dikaitkan dengan simbol kebersihan, keselamatan dan kualitas tinggi yang membuat konsumen tertarik karena proses pembuatan kosmetik yang diproduksi dibawah kondisi higienis yang ketat menurut Good Manufacturing Practice (GMP) dan kesehatan masyarakat ${ }^{18}$.

Label halal sangat penting sebanyak 45.94\%. Kepedulian responden terhadap label halal pada produk kosmetik ini sesuai dengan peraturan RI No 34 Tahun 2014 pada 67 yang 
Tabel VI. Hubungan label halal dan tulisan alkohol pada kemasan saat membeli kosmetik

\begin{tabular}{lccc}
\hline Kategori & \multicolumn{2}{c}{ Mempengaruhi saat membeli } & p-value \\
& Ya & Tidak & \\
\hline Logo halal & & & 0,418 \\
$\quad$ Islam & 80 & 15 & \\
$\quad$ Kristen & 2 & 1 & 1,000 \\
Free alcohol & & & \\
$\quad$ Islam & 57 & 38 & \\
Kristen & 2 & 1 & \\
\hline
\end{tabular}

menyatakan bahwa "Kewajiban bersertifikat halal bagi produk yang beredar dan diperdagangkan di wilayah Indonesia sebagaimana dimaksud dalam pasal 4 . Terjadinya penurunan urgensi label halal sangat penting pada produk kosmetik dapat disebabkan oleh berbagai faktor seperti faktor kebutuhan, perilaku dan pengetahuan.

Pada penelitian ini $41.84 \%$ menjadikan kebutuhan merupakan faktor utama, dilanjutkan, kehalalan $24.49 \%$, kualitas $17.34 \%$, harga $13,26 \%$ dan brand $3,06 \%$. Hal paling dasar yang harus terpenuhi untuk melakukan keputusan pembelian adalah kebutuhan yang ditunjukkan dengan pengaruh positif dan p-valuenifikan terhadap keputusan pembelian artinya jika terjadi peningkatan kebutuhan maka akan meningkatkan keputusan pembelian secara pvaluenifikan $^{19}$.

Desain kemasan yang dimiliki suatu produk dapat menarik minat konsumen, baik berupa tulisan menarik ataupun gambar yang terdapat pada produk kemasan seperti label halal $83.67 \%$ dengan nilai $p$-value 0,418 dan pada tulisan free alcohol $60.20 \%$ dan nilai $\mathrm{p}$ value 1,000 (tabel VI) ternyata dapat mempengaruhi niat saat membeli kosmetik. Melalui nilai $p$-value diketahui tidak ada pengaruh agama responden terhadap label halal dan tulisan free alcohol.

Penelitian ini sesuai dengan penelitian terdahulu dimana terdapat perbedaan dalam niat beli produk kosmetik yang memiliki label halal dan kosmetik yang tidak memiliki label halal, dimana kosmetik yang memiliki label halal memiliki skor yang yang lebih tinggi dibandingankan kosmetik yang tidak memiliki label halal ${ }^{20}$. Selain hasil tersebut ternyata terdapatnya label halal pada suatu produk kosmetik dapat mempengaruhi persepsi individu mengenai kandungan alkohol pada kosmetik dengan hasil nilai pvalue 0,024. Hasil penelitian ini dapat diketahui bahwa logo halal yang berada pada suatu produk memiliki pengaruh yang positif terhadap persepsi individu terhadap suatu produk karena adanya logo halal pada suatu produk juga membantu masyarakat muslim dalam memilih produk agar terhindar dari yang diharamkan agama.

\section{KESIMPULAN}

Sebagian besar responden mengetahui sudah ada produk kosmetik halal di Indonesia yang disertai dengan kebiasaan responden yang pernah meilhat label halal pada kosmetik, walaupun urgensi label halal tidak sebesar pada produk pangan tapi hampir setengah responden menganggap bahwa label halal pada kosmetik sangat penting yaitu 46.94\%. Label halal pada kosmetik membuat persepsi baru bagi masyarakat yaitu kosmetik berlabel halal tidak mengandung alkohol sesuai dengan uji pearson correlation dengan nilai $\mathrm{p}$-value label halal 0,024 $<0,05$ sehingga label halal dapat mempengaruhi persepsi masyarakat terhadap kandungan alkohol pada produk kosmetik berlogo halal dimana $61.24 \%$ responden memiliki persepsi bahwa kosmetik berlabel halal tidak mengandung alkohol. Penelitian ini masih memiliki 
keterbatasan sehingga untuk penelitian selanjutnya bisa melakukan penelitian dalam skala populasi yang lebih luas karena pada penelitian ini hanya individu yang berada dilingkungan kampus. Bisa dilakukan pada masyarakat luas agar hasil yang didapat cukup mewakili keadaan yang sebenarnya.

\section{DAFTAR PUSTAKA}

1. Walgito B. Pengantar Psikologi Umum. Yogyakarta: CV Andi. 2010

2. Sadeeqa S. Sarriff A. Assessment of Knowledge, Attitude and Perception Among Hospital Pharmacists Regarding Halal Pharmaceuticals. Journal of Applied Pharmaceutical Scince. 2014;4(5):80-86

3. Nurdyastuti I. Teknologi Proses Produksi Bio-Ethanol. 2015;75-83

4. Sulaiman, F., 2016, Mengenal Industri Petrokimia, Utirta press, Jakarta

5. Fatwa Majelis Ulama Indonesia. Hukum Alkohol. Jakarta: Majelis Ulama Indonesia. 2009

6. Elmi MI.. Label Halal: Antara Spriritualitas Bisnis dan Komoditas Agama. Malang: Madani. 2009

7. Nurrachmi R. The Global Development of Halal Food Industry: A Survey. Tazkia Islamic Finance and Business Review. 2017;11(1):39-56

8. Alim SA. Mawardi MK. Bafadhal AS. Pengaruh Persepsi Label Halal dan Kualitas Produksi Terhadap Keputusan Pembelian Produksi Fesyen Muslim. Jurnal Administrasi Bisnis. 2018;62(1):127-134

9. Erdem E. Varinli I. Yildiz E. The level of Consumers' Awarness and Perception in Consumption of Halal Cerified Products. Europe Journal and Business and Management. 2015;7(16):65-75

10. Syariena A. Puziah H. Rapid Determination of Residual Ethanol in Perfumery Products Using Headspace Gas Chromatography-Mass Spectrometry. Middle-East Journal of Scientific Resears. 2014;22 (3): 431-435
11. Haq MW. Batool M. Ahsan SH. Qureshi NR. Alcohol Use In Mouthwash and Possible Oral Health Concerns. Journal of the Pakistan Medical Association. 2009;59(3):186-190

12. Sukristiani D. Pengetahuan tantang Kosmetika Perawatan Wajah dan Riasan pada Mahasiswa Jurusan Kesejahteraan Keluarga Falkutas Teknik Universitas Negeri Padang, Skripsi, Jurusan Kesejahteraan Keluarga Falkutas Teknik Universitas Negeri Padang. 2014

13. Silalahi E. Syarifuddin. Sudibyo M. Faktor-faktor yang Mempengaruhi Terhadap Pengetahuan tentang Lingkungan pada Siswa Tingkt SMP/MTS N dan SMA/MAN Aditiyata di Kota Labuhanbatu. Jurnal Pendidikan Biologi. 2016;5(3):146-153

14. Nur AZO. Pengaruh Perilaku Individu Terhadap Hidup Sehat. Majority.2015;4(7):109-113

15. Ismail RM. Global Issues and Challenges for The Halal Food Industy. Paper Presented on China (Ningxia) International Cooperation Forum. 2015

16. Mustafar M. Ismail RM. Othman SN. Abdulah R. A Study on Halal Cosmetic Awareness Among Malaysian Cosmetics Manufacturers. International Journal of Supply Chain Management. 2018;7(5):492-496

17. Hajipour B. Gharache M. Hamidizadeh MR. Mohammadian F. Raising Halal Cosmetic Awareness Among The Respective Consumers. International Journal of Academic Research in Business and Sosial Sciences. 2015;5(7): 338-348

18. Paendong M. Tielung M.V.J. Pengaruh Kebutuhan dan Gaya Hidup terhadap Keputusan Pembelian Ponsel Smartfren di Galeri Smartfren Cabang Manado. Jurnal Berkala Ilmiah Efisiensi. 2016;16(4):387-395

19. Putri TU. Mursitama TN. Furinto A. Abdinagoro SB. Does MUI Halal Logo Matter For Young Millennials? 
Persepsi Masyarakat Terhadap Kandungan Alkohol Pada Kosmetik

An Experiment Study in Cosmetic Mass Market Brand. International Journal of Scientific and Technology Research. 2019;8(9):888-890

20. Abdul M, Yahya M, Kamarulzaman S.A, Rahman M.M. The Perception of
Malaysian Consumers on the Importance of Halal Logo in Their Purchasing Decision. Journal of Humanities and Sosial Science. 2016; 21(10):8-13 